\title{
KEN ANGROK PENDIRI WANGŚA RĀJASA
}

\author{
Devan Firmansyah 1) \\ Program Studi Pendidikan Sejarah dan Sosiologi Ikip Budi Utomo Malang \\ devanfirmansyah@gmail.com \\ Yahmin 2) \\ IKIP Budi Utomo Malang \\ Yahmin@budiutomomalang.ac.id
}

\begin{abstract}
This research have a purpose to reveal Ken Angrok's figure in establish Tumapĕl's Kingdom and also Wangśa Rājasa's cause Ken Angrok establish this family's name in $13^{\text {th }}$ Century. In this research, have a research's methods can be use, that is historiography's methods. Historiography's methods consist of four stage. This stage is: 1) Heuristic (aggregation of data source, that is ancient inscription, manuscript, foreign's report and folklore); 2) Criticical Source (verify to accurate data source); 3) Interpretation (declension to various sata source); and 4) Historriography (writing about result's research into form about scientific activities). This research can be conclusion that is Ken Angrok succesfull fall out Kadiri's Kingdom and establish his kingdom and the new dynasty's name. Successful from Ken Angrok because the right political strategy and with support from the clergy, the leader from local's area and the leader from vilages in the east Kawi's Mountain and the legitimacy from politics pass through his wedding with Ken Dĕdĕs.
\end{abstract}

Keyword: Ken Angrok, Wangśa Rājasa, Kerajaan Tumapĕl.

\section{PENDAHULUAN}

Setelah pembagian Kerajaan
Mědang yang dilakukan oleh Raja
Airlangga menjadi dua yaitu Keraja-an
Janggala dan Panjjalu kepada para
putranya pada tahun 1052 M (Hinzler \&
Schoterman, 1979:483; Kusumadewi,
1988:74 dan Riana, 2009:333), di Jawa
telah terjadi dis-integrasi sosial-politik dan
juga da-lam beberapa aspek-aspek
lainnya.

Pertentangan tersebut terjadi sampai masa Kerajaan Kaḍiri akhir. Keraja-an Kaḍiri sendiri adalah penerus Kerajaan Panjjalu, yang keberadaan awalnya dapat diketahui lewat pra-sasti Padlĕgan tahun 1038 Śaka (11 Januari $1117 \mathrm{M}$ ) bersama dengan para rajanya menghiasi panggung sejarah Jawa (Tim Penulisan Sejarah Nasional II, 2010:286). 
Pada masa akhir Kerajaan Kaḍiri tersebut dan juga di tengah ketidakstabilan sosial-politik masa itu, lahirlah tokoh pembaharu yang dijuluki dengan nama "Ken Angrok" pada tahun 1104 Śaka (1182 M), sesuai informasi dari kitab Kakawin Nāgarakrtāgama tepatnya pada pupuh 40 baris pertama (Wibo-wo, 1981:38-40; Mulajana, 2006:364 dan Riana, 2009:203). Tokoh Ken Angrok tersebut diharapkan segenap masyarakat pada saat itu menjadi "Juru Selamat" atau "Ratu Adil" di Jawa agar bisa menyatukan kembali kedua kerajaan yang terus berperang bertahuntahun tersebut. Karena da-lam konsep pemikiran masyarakat Jawa, Ratu Adil timbul pada masya-rakat yang mengalami "kegoncangan sosial politik yang besar" (Dirjosu-wondo, 1984:125).

Maka, berdasar-kan uraian diatas yang menjadi fokus dalam penelitian ini, berkaitan de-ngan masa situasi kondisi dimana Ken Angrok berkiprah mendirikan Wangśa Rājasa.

\section{METODE}

Metode penelitian pada kaji-an ini menggunakan metode historio-grafi. Metode tersebut terdiri dari empat tahapan yaitu: a) Heuristik, yaitu suatu kegiatan menghimpun jejak-jejak masa lampau (dari studi pustaka dengan data berupa prasasti, naskah susastra, berita asing dan cerita rakyat, pen); b) Kritik Sumber, yaitu menyelidiki apakah jejak-jejak sejarah masa lampau itu otentik baik dalam bentuk maupun isinya; c) Interpretasi, yaitu menetapkan mak-na hubungan dari faktafakta yang diperoleh; dan d) Historiografi, yaitu penyajian dengan menyampaikan sintesa yang diperoleh di dalam bentuk suatu kisah (Notosusanto, 1971:17).

\section{HASIL DAN PEMBAHASAN}

Kesejarahan tokoh Ken Ang-rok beserta dinasti (wangśa) yang ia dirikan dapat dilacak melalui berba-gai macam sumber data primer tak langsung misalnya saja prasasti Ba-lawi dari tahun 1227 Saka (1305 M), prasasti Maribong (Trawulan II) dari tahun 1186 Śaka (1264 M), prasasti Kuśmala (Kandangan) dari tahun 1272 Śaka (1350 M), dan prasasti MūlaMalurung dari tahun 1177 Śa-ka (1255 M) (Tim Nasional Penu-lisan Sejarah Indonesia II, 2010:424).

Untuk kiprahnya secara lengkap mulai dari awal kelahiran-nya sampai ia meninggal dapat dili-hat dalam separuh bagian awal kitab susastra Sĕrat Pararaton (Kriswanto, 2009:10-59). Dan juga disinggung sekilas dalam Kakawin Nāgarakrtā-gama pada pupuh ke 40 bait ke 1 sampai ke 5 (Muljana, 2006:364-365). 
Serta tersirat sekilas dalam Ce-rita Rakyat

Polowijen: Joko Lulo dan Putri Ndedes (Suwardono, 2005:80-87).

Untuk keterangan mengenai sebutan pertama kali Wangśa Rājasa dapat dijumpai dalam prasasti Bala-wi dari tahun Śaka 1227 (1305 M) (Yamin, 1962:255). Rupanya nama Wangśa Rājasa memiliki sebutan la-in (sinonim) yaitu "Wangśa Girīn-dra" seperti yang disebut dalam "Ka-kawin Śiwarātrikalpa (Lubdhaka)" (Zoetmulder, 1985:460) dan "Kșiti-dhareśwarawangśa" dalam prasasti Waringin Pitu (Surodakan), Lem-peng 3a, Baris ke 2 dan 3 (Noorduyn, 1978:235 dan Mulajana, 1983:127).

Berdasarkan keterangan tersi-rat dalam bab pembuka Pararaton, Ken Angrok adalah anak dari pejabat Pangkur yang berasal dari barat Gu-nung Kawi yaitu Kerajaan Kaḍiri yang pindah ke sebelah lereng timur Gunung Kawi (Suwardono, 2013a:152-153 dan 2013b:101-145). Pangkur adalah jabatan bertugas un-tuk mengurusi pajak-pajak yang ma-suk ke perbendaharaan kerajaan. Pangkur termasuk dari golongan sa-lah satu "mangilala drwya haj", yai-tu mereka yang menikmati kekayaan raja, dalam arti "mendapat gaji tetap" dari perbendaharaan kerajaan (Tim Penulisan Sejarah Nasional II, 2010:230-231 dan
Yogi, 1996:34). Dengan demikian Ken Angrok masih berstatus bangsawan yang di dalam struktur mangilala drwya haji, Ken Angrok berstatus kula pangkur yaitu keluarga atau keturunan dari pejabat pangkur (Yogi, 1996:46).

Ken Angrok dalam usahanya mendirikan kerajaan baru dan wang-śa melewati berbagai macam tahapan politis dan berkoalisi dengan berba-gai pihak pendukungnya. Adapun proses-proses perjuangan yang ia la-kukan antara lain:

1) Belajar berbagai macam ilmu pengetahun seperti belajar baca tulis dan jenis-jenis aksara, sastra, penanggalan Śaka dan ilmu perhitu-ngan hari kepada seorang Pujangga (Janggan) di Desa Sagênggêng (Kris-wanto, 2009:21). la juga beguru ke-pada Pu Palot dari Desa Turyânta-pada ilmu membuat emas (Kriswan-to, 2009:31-33). Kemungkinan Ken Angrok juga diajarkan ilmu lain oleh $\mathrm{Pu}$ Palot. Hal ini dikarenakan $\mathrm{Pu} \mathrm{Pa}$-lot yang dalam kitab Tantu Pangge-laran, disebut Pu Tapa-Palet juga menguasai teknik keterampilan membuat candi beserta teknik ukir-ukirannya, membuat lumpang batu, dan membuat gua (Nurhajarini \& Su-yami, 1999:128-129).

2) Membuat kerusuhan dan meminta perlindungan serta duku-ngan kepada para tokoh berpengaruh di desa- 
desa. Bisa jadi tujuan Ken Angrok tersebut ialah agar kondisi wilayah timur Gunung Kawi menjadi chaos sehingga muda ia kontrol dan kuasai. Adapun daftar keonaran yang Ken Angrok lakukan dan terekam dalam Pararaton ialah mengilangkan kerbau milik kepala desa di Lebak, mendirikan markas begal bernama Sanja bersama dengan sahabatnya yang bernama Tuan Tita, memperko-sa gadis pencari tuak di Hutan Adi-yuga dan juga memperkosa gadis pe-mikat burung, menjadi perampok di Desa Lulumbang, mencuri di Desa Kapundungan, berbuat onar dan me-nikam orang di Desa Kabalon, men-curi Arca Penjaga di Desa Tugaran dan juga memperkosa anak kepala desanya. Walaupun berbuat onar Ken Angrok sempat mendapat perlindungan dari beberapa pihak, misalnya: Gagak Inget keturunan prajurit dari Desa Lulumbang, para pendeta di Desa Junwatu, penghulu dari Desa Kapundungan, kepala desa bernama Luki, Nini (nenek) dari Desa Paniti-kan (Suwardono, 2013b:24-31).

3) Menggalang koalisi de-ngan para mangilala drwya haji un-tuk menggulingkan kekuasaan Tung-gul Amětung yang merupakan ke-panjangan tangan dari pemerintah Kerajaan Kaḍiri di wilayah pendudu-kan Tumapĕl, sebelah timur Gunung Kawi. Dalam Pararaton tokoh-tokoh disekitar Ken Angrok bisa ditafsir-kan sebagai mangilala drwya haji karena peran pentingnya bagi kesuksesan politik Ken Angrok dalam mengkudeta Tunggul Amětung. Me-reka antara lain: Ki Lembong yang bisa ditafsirkan sebagai perwakilan masyarakat kelas pedagang (Warsito, 1966:23) atau tuha dagang yang ber-tugas untuk mengkoordinasi dan me-ngawasi para pedagang dalam struk-tur mangilala drwya haji (Yogi, 1996:63). Namun karena profesinya sebagai pencuri bisa juga ia ditafsir-kan sebagai juru rahasya dalam posi-si mangilala drwya haji. Juru raha-sya adalah orang yang terlatih dalam mengurus hal-hal yang bersifat raha-sia (double-agent, pen) (Yogi, 1996:44). Kemudian tokoh Bango Samparan, bandar judi dari Desa Karuman bisa ditafsirkan dalam po-sisi mangilala drwya haji ia adalah seorang juru/tuha juḍi yaitu kepala dari para petugas yang mengurus se-gala macam perjudian (Yogi, 1996:43). Warsito (1966:24) juga menafsirkan Bango Samparan adalah seorang pemimpin partai politik yang menguasai 'the underworld' dari Tu-mapěl. Selanjutnya ada tokoh Pu Gandring yaitu pandai besi yang bi-sa dikatakan termasuk golongan ma-ngilala drwya haji. Dalam mangilala 
drwya haji disebutkan beberapa jenis pandai besi, antara lain dhūra yaitu pandi besi, juru barata yaitu kepala dari para pengrajin logam, juru guśa-li/gośali yaitu kepala pandai emas, pandai mas yaitu pembuat/pengrajin mas, pandai tembaga yaitu pem-buat/pengrajin tembaga, pandai tam-ra yaitu pembuat/pengrajin besi, sungka pembuat alat senjata (Yogi, 1996:41-60). Dan tokoh terakhir yai-tu Kěbo ljo yang berprofesi sebagai seorang prajurit. Posisi Kěbo ljo da-lam struktur mangilala drwya haji belum dapat dipastikan, anmun ber-kenaan dengan profesinya sebagai prajurit, maka bisa jadi ia termasuk salah satu dari beberapa jenis posisi keprajuritan dalam mangilala drwya haji antara lain agilingan yaitu ten-tara istana yang menggunakan kereta perang, juru salit yaitu kepala para tentara atau penjaga pertahanan kera-jaan/ibukota, magalah yaitu tentara kerajaan yang bersenjatakan tombak, makițran yaitu orang atau tentara ke-rajaan yang tugasnya berkeliling menjaga keamanan istana, mamanah yaitu tentara kerajaan yang memba-wa panah sebagai senjatanya, pala-wang yaitu tentara kerajaan yang menjaga pintu gerbang, patarah ya-itu orang yang tugasnya mengurus perampok, purug yaitu tentara kera-jaan, dan tapukan yaitu tentara yang bersenjata lengkap (Yogi, 1996:37). Tokoh-tokoh tersebut sukses mem-bantu Ken Angrok dalam melengser-kan kekuasaan Tunggul Amětung da-lam kudetanya.

4) Melegitimasi kekuasaan melalui politik pernikahan dengan seorang Ken Dĕḍess. Pararaton me-nginformasikan bahwa Ken Dĕḍes disebut sebagai perempuan strī nā-riśwarī atau arddha nāriśwarī. Kata strī nāriśwarī memiliki pengertian yang sama yaitu 'perempuan termu-lia' atau 'wanita yang paling uta-ma'. Keistimewaan yang dimilikinya adalah siapapun yang menikahi, be-tapapun nestapanya dia akan menjadi raja besar (ratu anyakrawati) (Cah-yono, 2011:8). Kemudian julukan arddha nāriśwarī memiliki penger-tian seseorang yang mempunyai "ra-him agung dan luhur" yang kelak akan melahirkan tokoh-tokoh besar (Purwadi, 2004:79). Agus Sunyoto (2000:24-26) menafsirkan jika Ken Děḍĕs adalah anak dari penguasa "Pūrwwa" yang mengusir Raja Krta-jaya dari takhtanya di Bhūmi Kaḍiri seperti yang disebut dalam prasasti Kamulan. Jika demikian Ken Dĕḍes merupakan seorang "putri mahkota" dari sebuah kerajaan PraTumapĕl. Wajar jika Ken Angrok sangat me-nginginkannya guna melegitimasi tahktanya yang kemudian Ken Ang-rok 
berusaha menyelamatkannya dari cengkraman Tunggul Amětung yang menjadikannya istri pampasan (strī jarahan) ketika Tunggul Amětung mengusai Tumapĕl.

5) Merangkul golongan aga-mawan dan juga penguasa daerah un-tuk suksesi kekuasaan Ken Angrok. Dukungan terkuat Ken Angrok pada puncak kiprahnya untuk menjadi raja adalah dengan dibantu para golongan agamawan dan juga penguasa lokal. Adapu tokoh-tokoh yang membantu Ken Angrok tersebut yaitu: Janggan dari Desa Sagênggêng yang menga-jari Ken Angrok berbagai macam il-mu pengetahuan (Hardjowardojo, 1965:16). Kemudian ada tokoh Pu Palot dari Desa Turyântapada yang ahli membuat emas (Kriswanto, 2009:31-33). Dalam Tantu Panggela-ran tokoh ini disebut Pu TapaPalet, yaitu seorang pendeta Buddha yang juga menguasai berbagai macam keterampilan seperti keterampilan membuat candi beserta teknik ukir-ukirannya, membuat lumpang batu, dan membuat gua (Pigeaud, 1924:119-120 dan Nurhajarini \& Suyami, 1999:128-129). Walau tidak dijelaskan secara eksplisit namun de-ngan diculiknya Ken Děḍĕs oleh Tunggul Amětung, maka ayahnya yaitu Pu Pūrwa seorang pendeta Buddha Mahayana dari Panawijen (Kriswanto,
2009:39-43), jelas men-dukung Ken Angrok untuk meleng-serkan Tunggul Amětung. Tokoh be-rikutnya adalah Danghyang Lohga-we yang tinggal di Desa Taloka, se-orang penganut Agama Wișnu (Weș-ṇawa) yang mengajak Ken Angrok mengabdi kepada Tunggul Amětung dan juga memberitahu Ken Angrok mengenai cahaya strī nāriśwarī atau arddha nāriśwarī Ken Dĕḍĕs (Kriswanto, 2009:37-43). Dan terakhir adalah dukungan penuh dari para pendeta pengungsi dari Daha ibu-kota Kaḍiri yang menolak menyem-bah Krtajaya sebagai dewa. Mereka adalah dari golongan Śiwa (Śiwa-Siddhānta), Wișnu (Weșnawa), Bud-dha (Sogata), Bhujangga, Brāhmaṇa (Wipra) dan golongan R̦̣i memberi-kan tambahan nama nobatan Ken Angrok sebagai Bhațāra Guru yang sebelumnya sudah dinobatkan de-ngan gelar "Śrī Rājasa Bhațāra Sang Amurwabhūmi" untuk menghadapi kepongahan dari Raja Kṛtajaya yang sesumbar bahwa ia hanya bisa dika-lahkan oleh Bhațāra Guru (Kriswanto, 2009:53\&55). Dan terakhir menurut Suwardono (2013a:161 dan 2013b:161) dengan mengorelasikan pemberitaan Prasasti Pamotoh dan juga Pararaton dapat ditarik kesim-pulan bahwa pendukung serta peno-batan Ken Angrok di Gunung Lejar dilakukan oleh penguasa 
lokal yaitu Rakryan Pamotoh beserta pendu-kungnya dari wilayah timur Gunung Kawi. Dengan demikian semakin ku-at kedudukan Ken Angrok.

6) Bertindak sebagai Juru Se-lamat (Ratu Adil) Jawa dengan mem-berontak dan meruntuhkan kekuasa-an dan kezaliman Raja Kṛtajaya dan Kerajaan Kaḍiri yang semena-mena dan mengakibatkan disintegrasi so-sial-politik masyarakat Jawa pada sa-at itu. Yanto Dirjosuwondo (1984:125) menjelaskan bahwa Ratu Adil timbul pada masyarakat yang mengalami "kegoncangan sosial politik yang besar". Maka dari itu da-lam kegoncangan politik pada masa tersebut sosok Ken Angrok dengan dukungan berbagai macam golongan dan juga strategi politiknya yang jitu berhasil melengserkan kekuasaan Raja Kṛtajaya dan Kerajaan Kaḍiri dalam pertempuran di Gantěr sekaligus menguasai seluruh Pulau Jawa pada tahun 1144 Śaka (1222 M) (Hardjowardojo, 1965:30-31). Dengan demikian Ken Angrok ber-hasil mendirikan kerajaan baru yaitu Kerajaan Tumapĕl dengan wangśa-nya yang baru pula yaitu Wangśa Rājasa.

\section{KESIMPULAN}

Tokoh Ken Angrok dikenal sebagai raja pendiri Kerajaan Tuma-pĕl sekaligus leluhur raja-raja Sing-hāsari-Majapahit. Ken Angrok juga mendirikan dinasti yang disebut de-ngan Rājasawangśa yang juga me-miliki nama lain yaitu Girīndra-wangśa atau Kșitidhareśwarawang-śa.

Kesejarahan Ken Angrok beserta dinastinya tersebut dapat dilacak melalui sumber data sejarah yaitu: (1) prasasti: Balawi; Maribong (Tra-wulan II); Kuśmala (Kandangan); Waringin Pitu (Surodakan); (2) nas-kah: Sĕrat Pararaton; Kakawin Nāgarakrtāgama; Kidung Harșa Wija-ya, dan Kakawin Śiwarātrikalpa (Lubdhaka); dan serta (3) "Cerita Rakyat Polowijen: Joko Lulo dan Putri Ndedes".

Namun karena sumber sumber data tersebut dianggap sebagai sumber data sekunder maka kesejarahan Ken Angrok sempat di-sangsikan oleh para sarjana barat. Namun dengan ditemukannya prasasti prasasti Mūla-Malurung pada tahun 1975 dan 2001 maka kese-jarahan Ken Angrok tidak perlu di-sangsikan lagi.

Ken Angrok berdasarkan ana-lisis diatas adalah anak dari pejabat Pangkur dari golongan mangilala dr-wya haji. Ken Angrok dapat menjadi raja karena menikah dengan Ken Dĕ-ḍes yang diduga adalah 
putri mah-kota penguasa wilayah timur Gunung Kawi (Pūrwwa/Tumapěl) dan juga mendapat Dukungan golongan agamawan, para mangilala drwya haji penguasa lokal, dan juga tokoh-tokoh pemuka desa. Ken Angrok dapat dikatakan adalah tokoh yang menjadi Juru Selamat atau Ratu Adil bagi masyarakat Jawa abad ke-13 M karena dapat mempersatukan Kera-jaan Kaḍiri (Panjjalu) dan Janggala sehingga tak terpisah kembali. Diha-rapkan kedepannya terdapat peneli-tian yang lebih lanjut untuk menguak tokoh Ken Angrok tersebut.

\section{DAFTAR RUJUKAN}

Cahyono, M.D. 2011. Ken Dedes "Stri Nariswari" Citra Kepribadian Wanita Ja-wa Kuna. Makalah di-presentasikan dalam "Be-dah Sejarah Ken Dedes" dalam Rangka Festival Ken Dedes di Polowijen, 8 Oktober 2011. Hal. 1-25. Malang: Dinas Kebu-dayaan dan Pariwisata Kota Malang.

Dirjosuwondo, Y. 1984. 'Mitos Ra-tu Adil Jawa sebagai Usaha Memberikan Motivasi Penyatuan Kembali Kerajaan Janggala dan Kediri'. Dalam Analisis Kebudayaan, Tahun IV, No. 1. Hal. 122135. Ja-karta: Departemen Pendi-dikan dan Kebudayaan.

Hardjowardjojo, R.P. 1965. Pararaton. Jakarta: Bhratara.

Hinzler, H.I.R., dan Schoterman, J.A. 1979. 'A Prelimi-nary Note on TwoRecently Discovered MSS of The Nāgarakṛtāgama'. Dalam Bijdragen tot de Taal-, Land- en Volkenkunde (B.K.I.)
[Journal of the Hu-manities and Social Sciences of Southeast Asia], Vol. 135, Issue 4. Hal. 481-484. Leiden: Brill Publishers in colla-boration with KITLV.

Kriswanto, A. 2009. Pararaton Alih Aksara dan Terje-mahan. Jakarta: Wedata-ma Widya Sastra.

Kusumadewi, S.A. 1988. Prasasti Garamán 975 Śaka (1053 Masehi). Skripsi belum diterbitkan. De-pok: Fakultas Sastra Ju-rusan IImu-IImu Sejarah Seksi Arkeologi-Univer-sitas Indonesia (FIB UI).

Muljana, S. 2006. Tafsir Sejarah Nagarakretagama. Yog-yakarta: LKiS.

Noorduyn, J. 1978. 'Majapahit in The Fifteenth Century'. Dalam Bijdragen tot de Taal-, Land- en Volken-kunde (B.K.I.) [Journal of the Humanities and Social Sciences of Southeast Asia], Vol. 134, Issue 2. Hal. 207-274. Leiden: Brill Publishers in collaboration with KITLV.

Notosusanto, N. (1971). NormaNorma Dasar Penelitian dan Penulisan Sejarah. (Seri Text-Book Sedjarah ABRI). Jakarta: Departe-men PertahananKeama-nan Pusat Sedjarah ABRI.

Nurharjarini, D.R., dan Suyami. 1999. Kajian Mitos dan Nilai Budaya dalam Tantu Panggelaran. Ja-karta: Departemen Pendi-dikan dan Kebudayaan.

Pigeaud, Th.G.Th. 1924. De Tantu Panggelaran. Een Oud-Javaansch Prozage-schrift, Uitgegeven, Ver-taald en Toegelicht. 's Gravenhage: Nederl. Boek en Steendrukkerii Voorheen H.L. Smits.

Purwadi. 2004. Strategi Politik Ken Arok. Yogyakarta: Gelombang Pasang.

Riana, I. K. (2009). Kakawin Dēśa Warṇnana Uthawi Nā-gara Krtāgama Masa Keemasan Majapahit. Jakarta: PT Gramedia.

Sunyoto, A. 2000. Petunjuk Wi-sata Sejarah Kabupaten Malang. Malang: Lingka-ran Studi Kebudayaan Malang.

Suwardono. 2005. Mutiara Budaya Polowijen Dalam Makna Kajian Sejarah, Cerita Rakyat, dan Nilai Tradisi. Malang: 
Dinas Kebudaya-an dan Pariwisata Pemerintah Kota Malang.

2013a. Sejarah Indonesia Masa Hindu-Bud-dha.Yogyakarta: Penerbit Ombak.

2013b. Tafsir Baru Kesejarahan Ken Angrok. Yogyakarta: Penerbit Om-bak.

Tim Nasional Penulisan Sejarah Indonesia II. 2010. Seja-rah Nasional Indonesia Jilid II: Zaman Kuno, Edisi Pemutahiran. Jaka-rta: Balai Pustaka.

Warsito, S. 1966. 'Benarkah Ken Arok Anak Desa?'. Dalam Madjalah Bulanan Pusa-ra, Djilid XXVII No. 3-4, Maret-April, 1966. Hal. 17-32. Yogyakarta: Pener-bit Taman Siswa.

Wibowo, A.S. 1981. 'Tahun Ke-lahiran Ken Anrok'. Hal. 38-40. Dalam Jurnal Ame-rta Berkala Arekologi, No. 4, Tahun 1981. Jakar-ta: Pusat Penelitian Arkeo-logi Nasional.

Yamin, H.M. 1962. Tatanegara Madjapahit Sapta-Parwa, Parwa I. Jakarta: Jajasan Prapantja.

Yogi, D. 1996. Mangilala Drwya Haji: Kedudukan dan Pe-rannya dalam Struktur Pemerintahan. Skripsi be-lum diterbitkan. Depok: Fakultas Sastra Jurusan II-mu-IImu Sejarah Seksi Ar-keologi-Universitas Indonesia (FIB UI).

Zoetmulder, P.J. 1985. Kalan-gwan: Sastra Jawa kuno Selayang Pandang. (Pe-nerjemah: Dick Hartoko SJ.). Jakarta: Penerbit Djambatan. 